\title{
Effect of False Confidence on Asset Allocation Decisions of Households
}

\author{
Swarn Chatterjee ${ }^{\mathrm{a}}$ \\ ${ }^{a}$ Associate Professor, Department of Financial Planning, Housing and Consumer Economic, \\ University of Georgia, Athens, GA 30602 United States
}

\begin{abstract}
This paper investigates whether false confidence, as characterized by a high level of personal mastery and a low level of intelligence (IQ), results in frequent investor trading and subsequent investor wealth erosion across time. Using the National Longitudinal Survey (NLSY79), change in wealth and asset allocation across time is modeled as a function of various behavioral, socio-economic and demographic variables drawn from prior literature. Findings of this research reveal that false confidence is indeed a predictor of trading activity in individual investment assets, and it also has a negative impact on individual wealth creation across time.
\end{abstract}

Key Words: Behavioral Economics, Cognitive Mistakes, Financial Decision, Investments, Portfolio allocation decisions.

JEL: D12; D14; G02

\section{(C) 2014 Published by SSBFNET}

\section{Introduction}

Self-efficacy refers to an individual's assessment of mastery in performing tasks successfully. Past findings indicate an association between self-efficacy or confidence and socioeconomic status and prestige (Gecas \& Seff, 1990). Overconfidence is defined as the overestimation of the probability of an event's occurrence (Liechenstein \& Fischoff, 1977). Peng and Xiong (2006) define overconfidence as high level of confidence in one's abilities along with the lack of ability to obtain or process related information. Overconfidence can also be defined as the over-calibration of one's abilities in performing tasks (Goldsmith \& Goldsmith, 1997). Past research provides evidence that overconfidence correlates strongly with frequent investor trading activity, portfolio underperformance and greater risky asset holding (Barber \& Odean, 2000, 2001, 2002; Peng \& Xiong, 2006). Results from another study of behavioral characteristics of online trading investors indicate that consumers who have a higher self-efficacy have greater confidence in their abilities and tend to invest in higher risk assets (Looney, Akbulut \& Poston, 2006).

Intelligence may be defined as the ability to process information, synthesize complex ideas, learn from past experiences, and to overcome obstacles by thinking rationally. However, there still exists considerable debate and disagreement among scholars regarding the absolute determination of intelligence (Sternberg \& Detterman, 1986). A

${ }^{i}$ Corresponding author 
popular approach to measuring individual intelligence is to measure a person's IQ, or intelligence quotient (Jones \& Bayley, 1941). McDaniel (2006) finds that states with higher level of IQ have higher median income have a lower percentage of their population living in poverty and generate larger gross state product per capita. Zagorsky (2007) finds IQ is positively associated with wealth accumulation. A high IQ score is also associated with quick mental processing of complex information (Bates \& Stough, 1998).

This implies that individuals who have a very high level of confidence along with a low level of intelligence are likely to be extremely overconfident when comparing the perception of ability to their actual ability in carrying out tasks. We define this type of overconfidence as false confidence. It follows that individuals who have false confidence are likely to have all of the traits of an overconfident individual along with a low level of intelligence. Hence, it can be expected that individuals with false confidence are more likely to exhibit behavior inconsistent with that of a rational investor as explained by Sharpe (1964). Our study investigates whether false confidence, as characterized by scores in the lowest quartile of intelligence (IQ) and personal mastery scores in the highest quartile, is a predictor of financial market participation and wealth accumulation among individual investors during 1998-2004. The purpose of this paper is to study whether false confidence is detrimental to the financial market participation and net worth of individuals during period of market volatility.

Hypotheses:

H1: Investors with false confidence are more likely to increase their market participation following a period of stock market rise and decrease their market participation following a stock market fall after controlling for a number of socioeconomic, demographic, and behavioral factors.

H2: Falsely confident investors are less likely than others to accumulate wealth during periods of market volatility after controlling for other socioeconomic, demographic, and behavioral variables.

\section{Methodology}

\subsection{Data Description}

This study uses the National Longitudinal Survey of Youth 1979 (NLSY79), a nationally representative panel data set containing economic, social, demographic and behavioral characteristics of 12,686 respondents managed by the Center for Human Resource Research, Ohio State University. This survey includes individuals born between 1957 and 1964 (Zagorsky, 2007). We include only respondents willing or able to estimate their net worth in both 1994 and 2004 NLSY samples. The years 1994 to 2004 are chosen because this time period represents a period in which the respondents of this survey entered the wealth formation phase of their life cycle.

\subsection{Dependent Variables}

The NLSY79 contains information on participants' stock holdings outside of their tax sheltered accounts. In order to measure the change in stock holding during this time period, the variables have been coded as follows: 
If (stockholding in 2000> stockholding in 1998) and (stockholding in 2004< stockholding in 2000) then stocktrading= " 1 " and " 0 " if otherwise.

The dependent variable for the second hypothesis is the change in net worth from 1998 to 2004. This period accounts for the time between the market peak, its subsequent fall and its resurgence. The net worth variable in NLSY is constructed using net worth questions asked in 1998 and 2004. These two logged wealth variables are then subtracted from each other to create a change in log from 2000 to $2004 \mathrm{~b}$.

\subsection{Independent Variables}

The independent variables include demographic, socio-economic and behavior related variables from the NLSY79 dataset. False confidence is the primary independent variable of interest. It is constructed by interacting the highest quartile of the Pearlin Mastery scale, which measures general self efficacy, with the lowest quartile of IQ. Pearlin scores are calculated by summing responses from the Pearlin Mastery scale included in the NLSY79 dataset. The scale is then split into four quartiles. The scores for those respondents that fall in the top are considered for constructing the false confidence variable. NLSY participants completed the Armed Services Vocational Aptitude Battery. These scores are then transformed into an intelligence percentile using the Armed Forces Qualifying Test.

The test is considered equivalent to an IQ test, and correlates strongly with other tests of cognitive ability (Chatterjee $\&$ Zahirovic-Herbert, 2010). The false confidence variable includes those respondents who fall in the bottom quartile of IQ and in the top quartile of the Mastery scale. The other control variables included in our model comprise of age, race, educational attainment, marital status, gender, income, amount of inheritance received, net worth, homeownership, being bankrupt, and being an entrepreneur. These variables are derived from the findings of prior literature (Haurin, Hendershott, \& Wachter, 1996; Keister, 2000; Zagorsky, 2007; Chatterjee, Salter, \& Harness, 2012; Chatterjee, 2013).

This study uses logistic regression to test the binary dependent variable for stock holding behavior in the first hypothesis. An ordinary least squares (OLS) regression is used to examine the change in net worth between 1998 and 2004.

\section{Results}

\subsection{Descriptive Statistics}

Table 1 provides descriptive statistics for false confidence and High confidence and intelligence (HCI). "False confidence" represents respondents who have their IQ in the lowest quartile and their self confidence in the highest quartile of Pearlin mastery scale. HCI comprises of respondents who have their IQ in the highest quartile and their self

\footnotetext{
${ }^{\mathrm{b}}$ Using the equation $\log _{\mathrm{b}} \mathrm{W}_{04}-\log _{\mathrm{b}} \mathrm{W}_{00}=\log _{\mathrm{b}}\left(\mathrm{W}_{04} / \mathrm{W}_{00}\right)$.
} 
confidence in the highest quartile of Pearlin mastery scale. The total sample size used for the purpose of this study is 5703, of which 2103 are primary household earners.

Table 1: Descriptive Statistics

\begin{tabular}{|c|c|c|c|c|}
\hline \multirow[b]{2}{*}{ Variables } & \multicolumn{2}{|c|}{ False confidence } & \multicolumn{2}{|c|}{$\mathrm{HCI}$} \\
\hline & $\mathrm{N}$ & Mean, $\%$ & $\mathrm{~N}$ & Mean, \% \\
\hline Log (Income) & 92 & 11 & 105 & 13 \\
\hline Log St.dev (Income) & 92 & 5 & 105 & 5 \\
\hline Log (Networth 04-00) & 92 & .30 & 105 & .45 \\
\hline Log St.dev( Stocks) & 92 & 10 & 105 & 8 \\
\hline \multicolumn{5}{|l|}{ Education } \\
\hline HS or below & 51 & $6 \%$ & 14 & $2 \%$ \\
\hline Some College & 23 & $4 \%$ & 15 & $3 \%$ \\
\hline College & 9 & $3 \%$ & 34 & $11 \%$ \\
\hline Graduate & 6 & $1 \%$ & 42 & $16 \%$ \\
\hline \multicolumn{5}{|l|}{ Race } \\
\hline White & 30 & $3 \%$ & 75 & $7 \%$ \\
\hline Black & 40 & $10 \%$ & 11 & $3 \%$ \\
\hline Hispanic & 18 & $6 \%$ & 7 & $2 \%$ \\
\hline Female & 31 & $4 \%$ & 33 & $4 \%$ \\
\hline Male & 61 & $5 \%$ & 72 & $6 \%$ \\
\hline Bankruptcy & 17 & $4 \%$ & 7 & $2 \%$ \\
\hline Widowed/diorced & 24 & $5 \%$ & 21 & $4 \%$ \\
\hline Married & 46 & $4 \%$ & 73 & $6 \%$ \\
\hline Non married & 46 & $5 \%$ & 32 & $4 \%$ \\
\hline Inherit & 17 & $3 \%$ & 48 & $8 \%$ \\
\hline Biz owner & 20 & $3 \%$ & 41 & $5 \%$ \\
\hline Home owner & 27 & $3 \%$ & 39 & $4 \%$ \\
\hline
\end{tabular}

3.2 Discussion of Means

Among the notable differences, primary income earning respondents with false confidence appear to have a lower mean of log income (11) than those respondents with higher intelligence and ability (13). Also, for networth change between 2000 and 2004, it appears that respondents with falseconfidence (.30) have a much lower ratio of networth in 2004 to networth in 2000, than respondents with high IQ and high confidence (.45). However, for standard deviation of stocks, it appears that individuals with falseconfidence tend to have a higher standard deviation (10) than individuals with high intelligence and ability (8). This may indicate that individuals with false confidence trade in and out of their investments more often. 


\subsection{Discussion of Frequencies}

For the education variable, a higher proportion of respondents in the high intelligence and confidence category have a college degree (11\%) or have been to graduate school (16\%) than individuals with false confidence, $3 \%$ of whom have been to college and only $1 \%$ have graduate degrees. Also, whites have a higher proportion of respondents in the high iq and confidence category (7\%), while blacks (10\%) and hipsanics (6\%) have a higher proportion of individuals with falseconfidence. Women and men are almost evenly split within falseconfidence and high IQ and ability category. For those who declared bankruptcy (4\%), or who were widowed or divorced (5\%), a higher proportion of individuals have false confidence. For respondents who are married, a higher proportion has higher intelligence and confidence (6\%) as compared to those with false confidence (4\%). However, for the non-married, the proportion of individuals with false confidence $(5 \%)$ is higher than it is for respondents with higher intelligence and ability (4\%). Also, a lower proportion of individuals who are homeowners and business owners have false confidence. Individuals with false confidence have a lower level of education, income and wealth than those with higher IQ and confidence. Also, individuals with false confidence have a higher standard deviation of stock holdings outside their tax sheltered accounts. This indicates that these respondents likely trade more frequently. The results of the descriptive statistics hint towards greater human capital formation among individuals with high IQ and confidence as opposed to those respondents with false confidence.

\subsection{Likelihood of Change in Stock Holding}

Table 2 shows the parameter estimates and the odds ratio from the logistic regression, which has been performed to study whether investor false confidence is a predictor of investing in stocks during a period following high recent returns (1998-2000 period) and subsequently holding a lower proportion of wealth in stocks after stock prices fell (2000-2004 period). The results show that investors with false confidence are significantly more likely (beta $=0.85, \mathrm{p}<$ .01 , Odds $=134.5 \%)$ to have a higher amounts invested in stocks when recent returns are high and have a lower amount of their wealth in stocks when recent stock returns are low, as compared to other groups. Among other variables, individuals who have moderate intelligence levels, with their IQ scores in the two middle quartiles are also more likely to have a higher amount invested in stocks during a period of recent high stock returns and have a lower amount invested in stocks during a period when the stock prices are low $(\mathrm{t}=0.01, \mathrm{p}<.1$, Odds $=1.1 \%)$. Also, total income earned is significant $(t=0.93, p<.01$, Odds $=151.31 \%)$, indicating that the individuals with higher income also invest in risky securities when stock prices have recently appreciated.

The results show that these high income investors experience reduction in the value of their stocks when the prices subsequently fell. Black respondents as compared to the reference group of white respondents have a significantly lower likelihood of engaging in such a behavior $(\mathrm{t}=-.42, \mathrm{p}<.1$, Odds $=-34.4 \%)$. This can perhaps be explained by the fact that black respondents have traditionally stayed away from high risk high return assets as compared to the reference group of white respondents (Keister, 2000). In addition, having children is a negative predictor $(\mathrm{t}=-0.11, \mathrm{p}<$ .1 , Odds $=-10 \%$ ) of trading in stocks during the period. This finding is similar to Keister, 2000, finding that having 
children reduces the probability of holding risky assets. Also, bankruptcy correlates negatively with risky asset holding during this period $(\mathrm{t}=-0.60, \mathrm{p}<.05$, Odds $=-45.1 \%)$.

Table 2. Logit Analysis of change in stock holding

\begin{tabular}{lrrc}
\hline & Beta & Odds & Significance \\
\cline { 2 - 4 } IQ & 0.011 & $1.10 \%$ & $*$ \\
False confidence & 0.853 & $134.50 \%$ & $* * *$ \\
Pearlin & 0.053 & $5.40 \%$ & $* *$ \\
HCI & -0.324 & $-27.70 \%$ & \\
Log totalincome & 0.922 & $151.30 \%$ & $* * *$ \\
female & .001 & $0.10 \%$ & $*$ \\
Black & -0.421 & $-34.40 \%$ & \\
Hispanic & -0.371 & $-31.00 \%$ & \\
Father's Education & 0.029 & $2.90 \%$ & \\
Mother's Education & 0.051 & $5.20 \%$ & \\
Age & -0.009 & $-1.00 \%$ & \\
College & 0.271 & $31.20 \%$ & \\
Graduate & 0.188 & $20.60 \%$ & \\
Homeowner & -0.086 & $-8.20 \%$ & \\
Married & -0.085 & $-8.20 \%$ & \\
Children & -0.105 & $-10.00 \%$ & $*$ \\
Inheritance & 0.1303 & $14.00 \%$ & \\
Bankruptcy & -0.5909 & $-45.10 \%$ & \\
Business Owner & 0.1201 & $12.80 \%$ & \\
\hline
\end{tabular}

The second part of the hypothesis tests whether false confidence is a predictor of respondents' portfolio volatility in terms of their stock holdings. If the standard deviation of the stock portfolio is greater than the median it is coded as ' 1 ' and as ' 0 ' if otherwise. The results are shown in table 3. False confidence is a significant predictor of frequent trading activity (beta $=1.09, \mathrm{p}<.01$, Odds $=197.1 \%$ ). This indicates that false confidence leads to significantly higher volatility of stocks in an individual's portfolio. This finding also confirms results of past studies on overconfidence, which find that overconfident investors are more likely to have a high variance in their portfolio of stocks (Barber \& Odean, 2001). However, unlike the past studies, no significant gender difference is found in this study. 
Table 3. Logit of stock holding volatility

\begin{tabular}{lrrr}
\hline & Beta & Odds & Significance \\
\cline { 2 - 4 } IQ & 0.0198 & $2.00 \%$ & $* * *$ \\
False confidence & 1.089 & $197.10 \%$ & $* * *$ \\
HCI & 0.3163 & $37.20 \%$ & \\
Pearlin & 0.0171 & $1.70 \%$ & $* * *$ \\
Log (income) & 0.6772 & $96.80 \%$ & \\
Female & -0.1534 & $-16.60 \%$ & \\
Father's Education & 0.0101 & $1.00 \%$ & $*$ \\
Mother's Education & 0.0422 & $4.30 \%$ & $*$ \\
Black & -0.6212 & $-46.30 \%$ & $*$ \\
Hispanic & -0.6279 & $-46.60 \%$ & \\
Age & -0.09 & $-8.60 \%$ & \\
College & 0.3729 & $45.20 \%$ & \\
Graduate & 0.2208 & $24.70 \%$ & $* *$ \\
Married & 0.2025 & $22.40 \%$ & \\
Children & -0.1513 & $-14.00 \%$ & \\
Inherit & 0.0378 & $3.90 \%$ & \\
Bankruptcy & -0.5557 & $-42.60 \%$ & \\
Business Owner & -0.3638 & $-30.50 \%$ & \\
Home Owner & 0.191 & $21.00 \%$ & \\
\hline
\end{tabular}

These results confirm the first hypothesis that people with false confidence are more likely to increase investment following periods of high recent returns. The investors with false confidence purchased stocks when the prices were high and subsequently reduced their stockholding, either through loss in value of the invested securities held by them or by selling the stocks at a lower price, when the prices dropped. These findings provide further evidence that individuals with false confidence are likely to have an exaggerated perception of their investment capabilities which may not be commensurate with their investment knowledge and intelligence. As a result, investors with false confidence are likely to make investment decisions that are not optimal and end up with a significant decrease in the value of their stock portfolio in times of an economic downturn, such as the one that was experienced between 2000 and 2004. It is also possible that this fall in falsely confident investor's stock holding is due to the disposition effect (Statman, Thorely, \& Vorkink, 2004), where an investor holds on to the loss making investments longer than necessary and sell off the profitable investments during periods of uncertainty and market downturn. Among other significant findings, income is a positive predictor of standard deviation of stock holding or volatility (beta $=.68$, $\mathrm{p}<.001$, Odds $=97 \%$ ), indicating that higher income individuals have greater risk tolerance and are willing to have a greater volatility in their portfolio of stocks. The second and third quartiles of IQ are also significant (beta $=.02$, $\mathrm{p}<.001$, Odds $=2 \%$ ). Blacks (beta $=-62, \mathrm{p}<.001$, Odds $=-47 \%$ ) and Hispanics (beta $=-63, \mathrm{p}<.001$, Odds $=-47 \%$ ) are less 
likely to trade frequently in stocks as compared to the reference group of whites. This can be explained by the fact that minorities tend to have a lower participation rate in high risk, high return assets as compared to whites (Keister, 2000). Also, age (beta $=-0.1, \mathrm{p}<.05$, Odds $=-8.6 \%$ ) and number of children (beta $=-0.15, \mathrm{p}<.05$, Odds $=-14 \%$ ) are negative predictors of frequent trading activity. Past research shows that individuals with greater number of children are less likely to hold risky assets (Keister, 2000).

\subsection{Determinants of Change in Networth 2000-2004}

The second hypothesis tests whether investors with false confidence end up with lower wealth across time. Research shows that if a diversified investment portfolio comprising financial assets such as stocks, bonds or mutual funds is held across time (without trading frequently), it is likely to generate greater returns and result in wealth accumulation (Barber \& Odean, 2000). However, as the theory suggests and by observing the findings of hypothesis one, it can be stated that investors with false confidence are likely to trade frequently and underestimate the risk of their investment assets. Therefore, it is expected that they will end up with significantly lower wealth, especially during periods of market uncertainty, such as the 2000-2004 period. In order to test the second hypothesis, difference in the $\log$ transformed networth between 2000 and 2004 is used as the dependent variable. A multivariate regression analysis is used to test whether false confidence is a predictor of wealth loss across time, after controlling for other demographic, socio economic and financial variables.

Table 4 shows the results from the ordinary least squares multivariate regression analysis, with log of change in net worth as the dependent variable is shown. The change in net worth variable has been log transformed, in order to remove bias due to outlier effects. The results indicate that false confidence (beta $=-0.34, p<.05$ ) is a predictor of wealth loss across time. This indicates that investors with false confidence experience a fall of $34 \%$ in the ratio of networth in 2004 as compared to the networth in 2000. This result confirms the second hypothesis, that individuals with false confidence experience a significant drop in wealth during the 2000-2004. 
Table 4. Hypothesis 2 Log Networth change 00-04

\begin{tabular}{|c|c|c|c|}
\hline Variables & Beta & St. Error & Significance \\
\hline False confidence & -0.34 & 0.17 & ** \\
\hline IQ & 0.00 & 0.00 & \\
\hline $\mathrm{HCI}$ & -0.07 & 0.13 & \\
\hline Pearlin & 0.02 & 0.01 & ** \\
\hline Father's education & -0.01 & 0.01 & \\
\hline Mother's education & 0.00 & 0.01 & \\
\hline Logtotalincome & 0.52 & 0.06 & *** \\
\hline Black & -0.26 & 0.09 & $* * *$ \\
\hline Age & 0.01 & 0.01 & \\
\hline College & 0.11 & 0.09 & \\
\hline Graduate & 0.15 & 0.09 & * \\
\hline Lognw00 & -0.60 & 0.02 & $* * *$ \\
\hline Married & -0.01 & 0.07 & \\
\hline Children & -0.05 & 0.02 & ** \\
\hline Inherit & 0.14 & 0.06 & ** \\
\hline Female & -0.10 & 0.07 & \\
\hline Bankruptcy & -0.36 & 0.10 & *** \\
\hline Business owner & 0.30 & 0.14 & $* *$ \\
\hline Home Owner & 0.23 & 0.07 & $* * *$ \\
\hline
\end{tabular}

Among other significant findings, income is a positive predictor of wealth creation (beta $=.52, \mathrm{p}<.05$ ) and graduate education is a significant predictors of wealth accumulation across time when recovering from an uncertain economic scenario. Also, inheritance (beta $=.14, \mathrm{p}<.05$ ) is a positive predictor of change in wealth. Past studies conducted in the eighties have found that inheritance increases wealth by $10 \%$ to $18 \%$ (Menchik \& David, 1983). The findings of this paper indicate that those who have received inheritance have increased their net worth by $14 \%$. Also, consistent with the Hurst and Lusardi (2004) study, business ownership (beta $=.30, \mathrm{p}<.05$ ) is a significant predictor of wealth accumulation after controlling for other variables. Homeownership is also found to be a significant predictor of wealth change (beta $=.23, \mathrm{p}<.05$ ). Among other control variables, African Americans (beta $=-.26, \mathrm{p}<.01$ ) have a lower wealth accumulation than whites and those who have filed for bankruptcy (beta=-.36, $\mathrm{p}<.01$ ) have a lower wealth accumulation than the control group. Also number of children (beta $=-.05, p<.05)$ was negatively associated with a positive change in networth during this period.

\section{Conclusion}

The findings of this study indicate that false confidence is a predictor of volatility in stock holdings within one's portfolio and increased investment following years of strong equity performance followed by decreased investment during a period following low returns. These findings are consistent with prior findings and theory that investors who are overconfident are likely to mistake aggregate equity performance with individual skill, leading to misguided attempts to enhance performance through frequent trading (Barber \& Odean, 2000). As a result, when the market falls 
they suffer a significant loss from the devaluation of these assets. Also, in accordance with prospect theory and disposition effect (Statman, Thorely, \& Vorkink, 2004), individuals tend to hang on to their loss making investments and sell off their profitable ones adding further to their wealth loss. One of the limitations of this study is that in the NLSY database, the response rate to the financial asset ownership questions has been low. In the future this study can be replicated for other periods, to study whether false confidence also affects investor wealth accumulation and asset allocation over a longer horizon of ten years or more. At a time when a large section of this nation's population prepare for retirement, the trait of false confidence needs to be researched further to study the deviation between an individuals perception of retirement preparedness and their actual level of preparation. The findings of this study provide both encouragement and opportunity to further study this area of behavioral finance, which can provide greater insight into the behavioral differences in household wealth allocation and investment choice.

\section{References}

Barber, B \& Odean T (2000) Trading Is Hazardous To Your Wealth: The Common Stock Investment Performance of Individual Investors. The Journal of Finance, Vol. 55(2), pp. 773-805.

Barber, B \& Odean, T (2001). Boys will be Boys. The Quarterly Journal of Economics, Vol. 116(1), pp.261-290.

Barber, B \& Odean, T (2002) Online Investors: Do The Slow Die First? Review of Financial Studies Special, Vol. 15(2), pp 455-487.

Bates, T.C. \& Stough, C.K. (1998). Improved reaction time method, information processing speed, and intelligence. Intelligence, Vol. 26(1), 53-62.

Chatterjee, S. (2013). Borrowing decisions of credit constrained consumers and the role of financial literacy. Economics Bulletin, Vol. 33(1), 179-191.

Chatterjee, S., Salter, J., \& Harness, H. (2012). Annuitization decisions of retirees: The role of risk aversion and financial advice. Review of Economic and Business Studies, Vol. 9(1), 35-51.

Chatterjee, S., \& Zahirovic-Herbert, V. (2010). Retirement planning of younger baby-boomers: Who wants financial advice?. Financial Decisions, Vol. 22(2), 1-12.

Gecas, V., \& Seff, M. A. (1990) Social class and self esteem: Psychological centrality, compensation, and the relative effects of work and home. Social Psychology Quarterly, Vol.53, pp.165-173.

Goldsmith, R \& Goldsmith, E (1997) Gender Differences in Perceived and Real Knowledge of Financial Investments, Psychological Reports, Vol. 80(2), pp. 236-238.

Haurin, D.R., Hendershott, P.H., \& Wachter, S.M. (1996). Borrowing constraints and the tenure choice of young households. NBER working paper. 5630, National Bureau of Economic Research, Inc.

Hurst, E., \& Lusardi, A. (2004). Liquidity constraints, household wealth, \& entrepreneurship. Journal of Political Economy, Vol. 112(2), 319-347.

Jones, H. E., and Bayley, N. (1941). 'The Berkeley Growth Study." Child Development, Vol.12, pp.167-173.

Keister, L.A. (2000). Race and wealth inequality: The impact of racial differences in asset ownership and distribution of household wealth. Social Science Research, 29, 477-502. 
Liechenstein, S. and B. Fischoff (1977) Do Those Who Know More Also Know More

About How Much They Know? The Calibration of Probability Judgments

Organizational Behavior and Human Performance, Vo. 20(2), pp.159-83

Looney, C, Akbulut, A and Poston, R (2006). A Study of Online Investing. Proceeds of Hawaii International Conference on System Sciences.

McDaniel, M (2006) State Preferences for the ACT versus SAT Complicates Inferences about SAT Derived State IQ Estimates: A Comment on Kanazawa, Journal of Intelligence, Vol. 34, pp 601-606.

Menchik, P.L., \& David, M. (1983). Income distribution, lifetime savings, \& bequests. American Economic Review, Vol. 73(4), 627-690.

Peng, L \& Xiong, W (2006) Investor Attention, Overconfidence and Category Learning Journal of Financial Economics, Vol 80, pp 563-602

Sharpe, W (1964) Capital Asset Prices: A Theory of Market Equilibrium Under Conditions of Risk, The Journal of Finance, Vol. 19(3), pp. 425-442

Statman, M, Thorely, S \& Vorkink, K (2004) Investor Overconfidence and Trading Volume, Review of Financial Studies, Vol.19(4), pp. 1531-1565

Sternberg, R. J. \& Detterman, D.K. (Eds.). (1986). What is intelligence? Contemporary viewpoints on its nature and definition. Norwood, NJ: Ablex

Zagorsky, J, L (2007) Do You Have to be Smart to be Rich? The Impact of IQ on Wealth Income and Financial Distress Intelligence, Vol 10, pp.1-13. 